\title{
Prazer sem camisinha: novos posicionamentos em redes de interação online*
}

\author{
Luís Augusto Vasconcelos da Silva**
}

\begin{abstract}
Resumo
Este artigo origina-se de uma pesquisa online sobre os discursos $e$ práticas do barebacking no cenário brasileiro. Neste trabalho discuto algumas comunidades da internet que ressaltam os aspectos positivos do sexo sem camisinha, sem necessariamente serem identificados ou vinculados ao conceito de barebacking. De modo geral, o que ligará todos os discursos (sexo sem camisinha e barebacking) é a busca por experiências mais naturais e livres, sensações e prazeres mais intensos. Portanto, o que está em jogo no sexo desprotegido é a possibilidade de maximização do prazer no contato mais íntimo com o outro.
\end{abstract}

Palavras-chave: Barebacking, Sexo Desprotegido, Corpo, Transgressão, Prazer.

\footnotetext{
* Recebido para publicação em setembro de 2008, aceito em maio de 2010.

** Professor Adjunto do Instituto de Humanidades, Artes \& Ciências, Universidade Federal da Bahia. Doutor em Saúde Pública pelo Instituto de Saúde Coletiva, UFBA. luisvascon@uol.com.br
}

cadernos pagu (35), julho-dezembro de 2010:241-277. 
Prazer sem camisinha

Pleasure without Condom:

New Positionings on Online Interaction Networks

\begin{abstract}
This article originated in online research about the discourses and practices of "barebacking" in the Brazilian context. In this work, I discuss some communities on the internet that highlight the positive aspects of unprotected sex, without necessarily being identified or linked to the concept of barebacking. In general, what connects these discourses (sex without condoms and barebacking) is the search for more natural and free experiences - sensations and pleasures that are more intense. Therefore, I conclude that what is central to unprotected sex is the possibility of maximization of pleasure in the most intimate contact with one's partner.
\end{abstract}

Key Words: Barebacking, Unprotected Sex, Body, Transgression, Pleasure. 
Luís Augusto Vasconcelos da Silva

\section{Introdução: a positividade do risco}

Este artigo é oriundo de uma tese de doutorado (2004-2008) sobre os discursos e práticas do barebacking entre usuários da internet, no cenário brasileiro. ${ }^{1}$ Neste artigo, proponho apresentar alguns discursos da internet que fazem "apologia" ou ressaltam os aspectos positivos do sexo sem camisinha, sem necessariamente serem identificados ou vinculados ao conceito de barebacking. Dessa forma, busco discutir a relação (e aproximação) desses discursos com as práticas contemporâneas do barebacking, compreendido como o sexo anal desprotegido entre homens de forma intencional (Suarez \& Miller, 2001; Halkitis, Parsons \& Wilton, 2003; Elford, 2006), ainda que haja diferenças (e ambiguidades) quanto ao tipo de vínculo e condição sorológica dos parceiros envolvidos.

Mansergh et alii (2002) definem barebacking como o sexo anal intencional entre homens que não são parceiros primários sem o uso do preservativo e destacam alguns aspectos centrais: a intencionalidade do comportamento, o sexo anal desprotegido, o tipo de parceria sexual e o contexto, que não deve ocorrer em uma situação de proteção negociada. Wolitski (2005) estabelece uma definição alternativa de barebacking: sexo anal sem preservativo de forma intencional, exceto quando praticado por parceiros primários HIV negativo que mantêm um relacionamento mutuamente monogâmico ou em um relacionamento de proteção negociada. Dessa forma, o autor busca incluir diferentes tipos de sexo anal desprotegido de forma intencional, por exemplo, entre parceiros primários sorodiscordantes ou entre parceiros primários soroconcordantes HIV positivo, na medida em que as relações possam apresentar risco para algum dos parceiros.

Desde o início desta minha trajetória de pesquisa, reconheci que era possível existir ganhos efetivos (e afetivos), sob a forma de

1 A tese foi defendida em abril de 2008, no Instituto de Saúde Coletiva (UFBA), sob a orientação do Prof. Dr. Jorge Iriart. Parte deste trabalho foi desenvolvida em estágio na UQAM (Canadá), financiado pela CAPES, sob a orientação do Prof. Dr. Joseph Lévy. 
emoções intensas, nas práticas sexuais desprotegidas, que superam ou são mais fortes que a ideia ou possibilidade de infecção pelo HIV. Um aspecto, portanto, mostrava-se central para a minha discussão: no sexo desprotegido, parece ocorrer a valorização de uma experiência corporal, sensorial, que se concretiza a partir de um contato mais intenso com o outro, um prazer excedente que surge pela expansão e transgressão das fronteiras e limites do próprio corpo. Com a realização desse prazer, as pessoas parecem adquirir maior autonomia e liberdade frente às normas e discursos socialmente estabelecidos, como a ideia de risco como ameaça ou perigo, ou seja, resultados negativos ou indesejados que devem ser evitados (Douglas 1994; Lupton, 1999; Lupton \& Tulloch, 2002). Nas sociedades contemporâneas, portanto, uma nova trajetória de positividade do risco (Le Breton, 2000, 2002; Lupton, 1999; Spink, 2001) passa a coexistir com os discursos que procuram ressaltar seus aspectos negativos em direção às perdas e catástrofes que afetam tanto os atores humanos quanto os ambientes em que vivem.

Segundo Lupton (1999:148), a ênfase das sociedades ocidentais contemporâneas em evitar o risco está fortemente associada ao ideal do corpo civilizado, a um desejo crescente de controlar a vida, racionalizar e regular o self e o corpo, enfim, de evitar as vicissitudes do destino. Essa forma de discutir o risco está estreitamente vinculada às ideias de Mary Douglas (1991), ao enfatizar que as noções de poluição, pureza e perigo estão associadas à relação entre ordem e desordem social. As sociedades precisam demarcar fronteiras para organizar a vida social segundo determinados critérios, que podem mudar no tempo. Para garantir ou retomar uma ordem ou moral social, podemos redefinir as linhas ou fronteiras que separam o que é tido como limpo ou puro de um lado, repugnante ou impuro de outro lado, e assim sucessivamente. 
Nessa perspectiva, a partir das leituras de Douglas (1991) e Kristeva (1982), é interessante trazer o conceito de abjeto ${ }^{2}$ (abjeção) para discutir as fronteiras que separam os corpos e identidades. Como aponta Grosz (1994:192), Julia Kristeva utiliza as noções de pureza e perigo de Mary Douglas (1991) para criar uma teoria da abjeção, que busca, basicamente, questionar as condições sob as quais o corpo apropriado e limpo (social) emerge e os custos de sua emergência, bem como as funções dessa demarcação do corpo (apropriado e limpo) para a transmissão e produção de tipos específicos de corpos. Nada é em si mesmo sujo ou perigoso (Douglas, 1991), em outras palavras, imundo, desprezível ou abjeto, já que estas ideias dizem respeito ao que não está no seu lugar apropriado, que incomoda ou confunde a ordem (Grosz, 1994). Como esclarece Kristeva (1982:04), não é a falta de clareza ou saúde que causa abjeção, mas o que perturba a identidade, o sistema, a ordem, é o que não respeita fronteiras, posições e regras, enfim, ao que está no entre (in-between), ao que é ambíguo ou misturado.

A discussão sobre as formas de regulação do corpo $e$ o modo como aprendemos a nos posicionar frente ao risco e aos prazeres adquire novo sentido quando analisamos a maneira como a sociedade ocidental construiu seu processo civilizador (Elias, 1993). A trajetória de transformações de hábitos e costumes sociais afetou a forma como interagimos com a natureza e o perigo. $\mathrm{Na}$ transição das sociedades medievais para as sociedades modernas ocorreu uma reorganização da vida social, produzindo formas de conduta e sentimentos mais domesticados ou civilizados. Não podemos esquecer que, na pré-modernidade, o corpo/self foi concebido essencialmente como aberto, poroso ou permeável ao mundo, permitindo a troca constante de elementos de dentro e fora do corpo (Lupton, 1998).

Essa forma de conceber o corpo (e o mundo) esteve presente na concepção estética particular da vida prática na Idade

2 Do lat. abjectu, que significa imundo, desprezível, vil, baixo, ignóbil. 
Prazer sem camisinha

Média, o que Bakhtin (1970) denominou de realismo grotesco, ou seja, o sistema de imagens da cultura cômica popular. ${ }^{3}$ Segundo Bakhtin (1970:28), o princípio material e corporal do realismo grotesco vai de encontro a todo isolamento do indivíduo $e$ confinamento em si mesmo, a toda característica ideal abstrata, a todas as pretensões de significação que estejam separadas $e$ independentes da terra e do corpo. Nessa perspectiva, o corpo grotesco não está separado ou fechado para o restante do mundo, tampouco acabado ou pronto, ele ultrapassa a si mesmo, transpõe seus próprios limites. A ênfase é colocada sobre as partes do corpo abertas para o mundo exterior, através de seus orifícios, protuberâncias, ramificações e excrescências (Bakhtin, 1970:35); por conseguinte, conectado com outros seres e coisas do mundo.

Já no século XVI, com a reforma protestante, mas principalmente no final do século XVII, com o iluminismo, passa-se a questionar o papel da natureza, do corpo, sua sensualidade, as superstições e o sobrenatural, em direção a um pensamento mais racional e científico (Lupton, 1998). O corpo/self torna-se, gradativamente, mais fechado para o mundo, revelando uma preocupação crescente com a regulação $e$ autocontrole $e$, consequentemente, um sentimento de ansiedade em torno do relaxamento e perda de controle das fronteiras do corpo/self (Lupton, 1998). De certa forma, os indivíduos aprendem a calcular algumas reações afetivas. O corpo deixa de estar aberto às

3 Mikhail Bakhtin (1970), na obra sobre Rabelais e a cultura popular na Idade Média, coloca em evidência algumas das imagens cômicas que perturbaram a ordem hierárquica da cultura oficial na Idade Média. É interessante discutir como o corpo foi vivido no cotidiano daquela cultura popular, principalmente em um dos contextos transgressivos mais importantes - a carnavalização do mundo. Em oposição às festas oficiais, o carnaval aparece como um tipo de libertação provisória de uma verdade dominante e abolição de todas as relações hierárquicas, privilégios, regras e tabus existentes. Como enfatiza Bakhtin, o carnaval era uma autêntica festa do tempo, no sentido de produzir uma situação nova, de mudança e renovação. Nessa perspectiva, o mundo carnavalesco se opunha à repetição, estabilidade e permanência, sendo hostil a tudo que é completo, pronto e acabado, a todas as pretensões de imutabilidade. 
paixões e aos prazeres, para fechar-se frente ao perigo do mundo não civilizado. De certa maneira, na saída do mundo medieval, a vida torna-se menos perigosa, na medida em que se restringe a satisfação direta do prazer (Elias, 1993).

Entretanto, conforme destaca Deborah Lupton (1998), não se pode dizer que a transição de um corpo aberto para mais fechado ocorreu de forma linear ou inexorável, sem descontinuidades ou rupturas. Em períodos de maior intensificação de controle e regulação das emoções surgiram também contradiscursos, colocando as emoções como fontes ponderosas de humanidade e autenticidade. O barebacking pode ser apresentado como uma dessas formas de ruptura $e$ atravessamento das fronteiras corporais, quando os prazeres sensoriais são destacados, principalmente no que diz respeito ao contato com o esperma. Na mesma direção, outros discursos mais genéricos passam a circular na internet fazendo alusão ao prazer máximo propiciado pelo "sexo natural" - o contato com a pele -, ao mesmo tempo em que ocorre uma explosão de discursos sobre o sexo seguro, estabelecendo limites às formas de obtenção do prazer.

\section{Considerações sobre a pesquisa on line}

Em 2006, após uma pesquisa de reconhecimento do campo no Orkut ${ }^{4}$, utilizando suas ferramentas de busca, encontrei algumas comunidades que discutiam as práticas do barebacking, bem como os aspectos positivos em relação ao não uso da

\footnotetext{
4 Filiado ao Google, o Orkut (www.orkut.com) tem se destacado no cenário brasileiro como uma rede social importante que permite pôr em relação os amigos de amigos, ou simplesmente criar novas amizades e manter relacionamentos, propiciando a circulação e a discussão de temas diversos. Lançado em 2004, o Orkut atualmente é muito difundido entre os usuários brasileiros. De acordo com Moraes \& Rocha (2005), em 2005, os brasileiros correspondiam a 71,8\% de uma comunidade de 6,2 milhões de pessoas.
} 
camisinha. ${ }^{5}$ Durante essa trajetória, como forma de acompanhar os grupos de discussão, foi criado um e-mail e uma página específica com as informações gerais sobre a pesquisa do meu doutorado. Vale ressaltar que já havia identificado $e$ acompanhava, desde junho de 2005, um grupo de discussão no Yahoo sobre o barebacking. ${ }^{6}$

Após aproximadamente um ano e cinco meses de observação participante online nas comunidades do Orkut (de abril de 2006 a setembro de 2007), integrei alguns fóruns criados diretamente para a discussão sobre o barebacking ou sobre o sexo sem camisinha. Ao longo desse período foram identificadas, registradas e acompanhadas na minha página do Orkut sete comunidades diretamente vinculadas ao tema do barebacking, uma delas posicionando-se contra a prática (NÃO AO BAREBACK, com 312 membros).

Vale lembrar que cada usuário do Orkut pode criar a sua própria comunidade ou participar de alguma já existente; em alguns casos, devendo ser aceito pelo moderador. Entre estas comunidades nas quais eu estava inserido, algumas delas, ao longo do tempo, deixaram de estar disponíveis. Até setembro de 2007 acompanhei três comunidades criadas para discussão e encontros de barebacking, registradas na seção do Orkut correspondente às minhas comunidades ${ }^{7}$ :

\footnotetext{
5 Como a discussão ou definição (geral) do barebacking girava em torno do sexo sem camisinha, busquei direcionar a pesquisa no Orkut a partir de enunciados ou palavras-chave (sem camisinha, bareback, barebacking, etc). Por sua vez, no momento em que uma comunidade é localizada, com seus respectivos membros, é possível, também, identificar outras comunidades que porventura estejam registradas na página desses membros, ou mesmo registradas na própria comunidade que foi localizada.

6 No Yahoo!Grupos, do Brasil, encontrei apenas uma comunidade de barebacking, que já não se encontra mais disponível na rede. Minha participação ocorreu entre junho de 2005 e julho de 2006, momento em que não conseguia mais localizar o grupo no endereço correspondente.

7 Com exceção da comunidade NÃO AO BAREBACK, as outras três que foram registradas na minha página deixaram de existir. Isso não significa que outras
} 
Luís Augusto Vasconcelos da Silva

1) Bareback - Brasil (165 membros). Categoria: Gays, Lésbicas e $\mathrm{Bi}$

SE J A M B E MVIN D OS

$B A R E B A C K$ - B R A S I L

Galera, esta comunidade é destinada a praticante de Barebacking, que é o sexo sem camisinha, com direito a gozar dentro de seu parceiro.

2) Bareback Sex: risco ou prazer? ${ }^{8}$ (175 membros). Categoria: Gays, Lésbicas e Bi

A ideia deste espaço é discutir uma (nova) prática sexual, o barebacking sex (literalmente "montar sem sela"; sexo intencional sem camisinha), que tem sido considerada como de alto risco para a transmissão do HIV entre homens que fazem sexo com outros homens (HSH). Ele se caracteriza por um envolvimento intencional/deliberado/voluntário e consciente (dos riscos envolvidos) em práticas sexuais sem o uso do preservativo.

A ideia é de que este seja um canal aberto à troca de experiências $e$ informações sobre práticas de risco em relação ao sexo. Caso você se identifique como um barebacker ou seja interessado em discutir tais questões, participe desta comunidade.

comunidades não foram ou não têm sido criadas ao longo desse período. Portanto, é importante enfatizar que as comunidades do Orkut não são fixas, podendo ocorrer muitas mudanças, incluindo a forma como são descritas e o número de participantes ou membros. Por exemplo, em 2010, a comunidade Bareback - Brasil passou a ter 769 membros. Essas novas comunidades e mudanças abrem possibilidades para outras discussões e pesquisas.

8 Esta comunidade apresenta uma descrição mais técnica em relação às demais. Alguns elementos, como a denominação de $\mathrm{HSH}$, prática sexual de alto risco para a transmissão do HIV, um envolvimento intencional/ deliberado/voluntário e consciente (dos riscos envolvidos), parecem envolver algum interesse em pesquisa ou intervenção, já que as outras comunidades utilizam uma linguagem ou repertório mais próximo do cotidiano, expressando algum desejo ou fantasia sexual de seus participantes. 
Prazer sem camisinha

3) Baryback (sx sem camisinha) (26 membros). Categoria: Outros.

É importante esclarecer que a maioria das comunidades do Orkut girava apenas em torno do sexo sem camisinha ou da preferência por gozar dentro, muitas vezes destacando os aspectos negativos do uso do preservativo. Na maioria delas, portanto, não havia nenhuma referência direta, na sua descrição, ao barebacking. Para minha surpresa, cheguei a encontrar no Orkut algo em torno de quarenta (40) comunidades mais genéricas ${ }^{9}$ que valorizavam positivamente o sexo sem camisinha. A estratégia de incluir na pesquisa comunidades que valorizavam ou ressaltavam os aspectos positivos do sexo sem camisinha foi importante para discutir algumas confusões ou ambiguidades em relação à própria definição ou entendimento do barebacking. Nesse sentido, passei a comparar e relacionar as comunidades mais específicas de barebacking com algumas mais genéricas, direcionadas para aqueles que detestavam usar a camisinha ou que enfatizavam os aspectos positivos, de maior prazer, implicados no sexo natural. ${ }^{10}$

Dessa forma, a relação entre sexo sem camisinha $e$ barebacking mostrava-se, muitas vezes, tensionada e de difícil separação, principalmente quando se observava o surgimento (e crescimento) de grupos de discussão online a destacar os ganhos sensoriais do sexo natural ou sem borracha. A própria definição de barebacking apresentava divergências entre alguns usuários $e$

9 Como pode ocorrer um fluxo contínuo nas redes de interação online, no mês de setembro de 2007, havia na minha página apenas vinte e cinco comunidades cadastradas, entre elas, aquelas criadas para discutir o barebacking e a preferência por engolir esperma. No que concerne apenas ao sexo sem camisinha, havia a existência de dezesseis comunidades, variando em torno de 14 a 2.836 membros.

${ }^{10}$ Busquei acompanhar aquelas comunidades onde já havia a participação de alguns membros, bem como a existência de pelo menos um fórum de discussão, preferencialmente com mais de uma postagem (mensagem), com o objetivo de registrar o fluxo de respostas, conflitos e interesses em foco. Deve-se, entretanto, ressaltar que as comunidades vinculadas diretamente ao tema do barebacking continuaram sendo a referência principal da tese de doutorado. 
meus interlocutores online. ${ }^{11}$ De modo geral, o conceito de barebacking girava em torno do sexo sem camisinha, na maioria das vezes desvinculado do tipo de parceria (fixo ou ocasional). Vale lembrar que essa prática sexual desprotegida (entre homens) esteve ligada à penetração anal (ativo ou passivo), enfatizando, principalmente, o contato direto com o esperma. Nessa perspectiva, nos discursos sobre o barebacking, a referência ao sexo anal desprotegido parece ser o ponto de partida para a análise, ainda que nem sempre exista clareza quanto à distinção entre sexo desprotegido de forma intencional (premeditado) $e$ casual ou acidental.

Em relação às comunidades organizadas apenas em torno do sexo sem camisinha, vale ressaltar que muitas delas eram descritas como grupo de Romances e Relacionamentos, de Atividades, de Esportes e Lazer, de Pessoas, Outros, etc. (categorias estas padronizadas e utilizadas pelo Orkut). Conforme identificado nas descrições das comunidades (ver exemplos acima), praticamente todos os grupos (e fóruns) de barebacking encontravam-se na categoria de Gays, Lésbicas e Bi (com exceção daquela denominada Baryback, descrita acima, onde consta a categoria de Outros). ${ }^{12}$

${ }^{11}$ Com a criação da minha página no Orkut, foi possível, também, solicitar a participação de voluntários para uma entrevista online, aberta, utilizando o recurso do MSN existente para a conversa em tempo real. Vale enfatizar que também deixei registrado, na minha página do Orkut, na seção correspondente ao perfil do usuário, meu endereço eletrônico para contato. Cada novo convite no MSN significava uma resposta positiva para participar da pesquisa, ainda que esses interlocutores pudessem desistir ou retirar seu consentimento a qualquer momento. Neste artigo, trago apenas os relatos referentes aos fóruns de discussão online, principalmente de algumas comunidades mais genéricas que destacavam o prazer no sexo sem camisinha. As narrativas produzidas a partir das minhas interações no MSN Messenger, em tempo real, com praticantes (e curiosos) do barebacking, não serão tratadas aqui. A pesquisa foi aprovada pelo Comitê de Ética em Pesquisa. Registro CEP: 025-07/CEP-ISC.

${ }^{12}$ Após o término da pesquisa, e mais recentemente, passei a encontrar outras comunidades de barebacking descritas em outras categorias do Orkut, como de Atividades, Outros e Pessoas. Estes "novos descritores" talvez signifiquem uma 
Prazer sem camisinha

No que concerne à dinâmica de participação e contato nas comunidades do Orkut, alguns aspectos merecem destaque. No momento em que cada membro do Orkut cria ou participa de alguma comunidade, todas elas ficam visíveis na página do usuário, no meu caso na página de Augusto Silva. Por sua vez, todos os membros de cada comunidade também ficam registrados e visíveis na página da comunidade. É muito fácil estabelecer contato, na forma de amigos, ou simplesmente enviar mensagens e depoimentos para cada participante. Quando um membro de uma comunidade participa de um fórum de discussão, ele pode ficar anônimo ou ser identificado imediatamente. Para mim, ser identificado foi uma forma interessante de outro membro entrar em contato comigo ou visitar a minha página e perfil.

No Orkut, é comum também encontrar membros que participam de várias comunidades simultaneamente, a partir de seus interesses em foco, como é o caso do barebacking. Periodicamente, também passei a receber convites de alguns membros para participar de sua rede de amigos (no Orkut, há uma seção correspondente da página em que os meus amigos ficam identificados, possibilitando que se estabeleçam redes de amizade ou contato). Nos fóruns, as mensagens, dispostas em uma sequência ordenada por data e hora de envio, também podem tomar a forma de um diálogo, quando os membros respondem uns aos outros. Frequentemente, as respostas acabam se direcionando para o tópico-guia do fórum em questão, ou mesmo para alguns dos participantes que enviam uma mensagem polêmica, por exemplo, criticando ou censurado a prática do barebacking.

É importante lembrar que vários dos signos e repertórios ${ }^{13}$ culturais que servem para diferenciar os interlocutores quanto aos

maneira de "deslocar" ou "enfraquecer" uma imagem associada ao barebacking como prática (exclusiva) de gays ou homossexuais.

${ }^{13} \mathrm{O}$ conceito de repertório interpretativo é aqui utilizado para designar a variabilidade de estratégias linguísticas, situadas em contextos diversos, para dar sentido ao mundo. Em outras palavras, o conjunto de conceitos, termos, 
seus múltiplos posicionamentos identitários, suas posições de gênero e sexual, também permitem abertura, ambiguidade $e$ flexibilidade na rede de posicionamentos online. Por exemplo, na página do Orkut, seus usuários podem permanecer no anonimato quando participam de um fórum, podem deixar seu respectivo link (nome, apelido ou nickname) para que qualquer participante possa localizá-lo na sua página pessoal, podem mostrar-se ambíguos em relação a suas preferências e identidades de gênero e sexual, ou simplesmente reconhecer a dificuldade do uso da camisinha ou o excesso de prazer quando não a usam. Mesmo na página pessoal de cada usuário, é possível criar um roteiro de identificação com o que for mais conveniente ou significativo para o propósito dos contatos e interações em jogo, como é o caso da categoria orientação sexual, podendo sugerir ou indicar a manutenção ou ampliação da rede de amigos a partir de algum critério (interesse) para o estabelecimento das relações. Nos fóruns de discussão online, portanto, as pessoas tentam traduzir as pistas ou indícios interpretativos sobre os membros das comunidades, seus pontos de vista e interesses a partir dos repertórios e signos disponíveis, incluindo imagens ou fotografias.

Existe, também, um repertório erótico disponível socioculturalmente que faz deslocar termos, convenções e sentidos do cotidiano (Parker, 1991). ${ }^{14}$ Nos contextos de interação online, mediante a possibilidade aberta de construção identitária,

vocabulários, descrições, figuras de linguagem etc. que demarcam o campo de possibilidades de construções discursivas (Spink \& Medrado, 1999; Spink, 2001). Esses repertórios devem ser compreendidos para além do campo da linguística, considerando os vários contextos ou formas de comunicação, por exemplo, imagens, símbolos e ícones utilizados na rede de interação online.

${ }^{14}$ Nos diferentes contextos de interação, palavras e enunciados que podem significar, em um determinado campo discursivo, agressividade, violência, vulgaridade, imoralidade, repugnância, inferioridade, objetos físicos, coisas da natureza, ou implicar uma convenção social, podem adquirir novos sentidos e valores, bem como inverter uma determinada ordem. É o caso da referência ao leite do homem, investido da capacidade de dar de mamar, ou mesmo em relação ao conceito de porra para se referir ao esperma masculino. 
Prazer sem camisinha

flexibilidade e descentramento do self, simulação, anonimato (Brown, Maycock \& Burns, 2005; Ross, 2005; Ross, Tikkanen \& Mansson, 2000; Turkle, 1999), essa dimensão transgressiva do erotismo pode ficar exacerbada, mais visível, ou parecer banal e repetitiva. A internet tanto pode reproduzir padrões interativos $e$ imagens valorizadas pela sociedade (Semerene, 1999), como também possibilitar a criação (ou imaginação) de novas formas de vida. Como sugere o conceito de heteroglossia (Bakhtin, 1998), é possível trazer para a internet uma multiplicidade de "vozes" ou uma extensa variedade de relações e interrelações, orquestrada dialogicamente, onde "forças centrípetas" (que unificam $e$ centralizam o mundo social) e "forças centrífugas" (processo ininterrupto de descentralização e diferença) se intersectam. Essa concepção dialógica possibilita perceber o que está na margem, incorporando as formas vivas da linguagem como processo formativo, flexível, cambiante.

Finalmente, chamo atenção que não há garantia de uma imagem verdadeira na internet, ainda que essas imagens sejam mediadas por referências socioculturais. Nessa perspectiva, as inscrições sobre a dinâmica (homo)erótica devem se pautar por critérios de verossimilhança, mais do que por um critério de verdade. Na direção de Rios (2003), acredito que os fatos ficcionais são potencialmente reais, na medida em que produzem efeitos, repercussões ou múltiplas respostas em seus ouvintes ou leitores.

Considerando a questão da verdade nos relatos sociais, Fry (1983) assinala a importância de se conhecer as representações coletivas e como se relacionam em uma rede social. Para o autor, é impossível averiguar a verdade de uma fofoca. A distinção entre o que se diz que acontece e o que ocorre de fato é uma preocupação teórica secundária. Para além de qualquer pretensão representacionalista, talvez seja mais proveitoso admitir que nossas descrições têm efeito sobre o mundo e também produzem coisas ou versões da realidade (Potter, 1997). 
No tempo acelerado da atualidade, sob o signo de uma modernidade líquida, caracterizado, entre outros aspectos, pela procura de satisfação instantânea, intensa, e pela possibilidade de escolha, as redes de interação online aparecem também como formas de flexibilização dos compromissos e obrigações (Bauman, 2004). Para além de uma análise pessimista dos novos parâmetros de "proximidade e distância virtual" (Bauman, 2004), é possível discutir ou compreender a cibersexualidade como espaço de disseminação de novos discursos e modelos sexuais (Lévy, Garnier $\&$ Thoer-Fabre, 2006). Portanto, a partir de uma perspectiva foucaultiana de explosão do sexo em discurso (Foucault, 2001), é possível focalizar a internet como abertura do campo sexual pela exploração de uma variedade de opções, na forma de textos e imagens - eróticos ou pornográficos - significando também a construção de um novo espaço político com suas modalidades diversas de resistência (Lévy, Garnier \& Thoer-Fabre, 2006).

\section{O sexo sem camisinha e seu "mundo de prazeres mil"}

No que diz respeito ao prazer nas situações que envolvem o risco para a infecção do HIV, chamo atenção para um aspecto importante na análise do risco: a ambiguidade e o atravessamento de fronteiras, como modos de transgressão, significam também excitação, êxtase, ou fonte de prazer. A relação entre limite (perigo) e transgressão é fundamental para discutir alguns tópicos ou justificativas para a realização do sexo desprotegido, mais precisamente do barebacking.

O que parece ser mais importante ou plausível em torno das diferentes práticas sexuais desprotegidas é que o prazer do contato ou de intimidade total do sexo sem borracha não se constitui de forma isolada ou completamente desvinculada das noções de perigo e desordem que o sexo (desprotegido) faz provocar, ainda que o prazer (e não o perigo) apareça de forma mais explícita em muitos dos textos online. O prazer do sexo desprotegido encontrase vinculado a uma trajetória perigosa ou arriscada, 
Prazer sem camisinha

principalmente porque pode significar ruptura da norma ou ordem social, bem como produzir um excesso de prazer pelo atravessamento ou mistura de fronteiras entre os corpos (Bataille, 2004). ${ }^{15}$

Não estou afirmando que os homens que praticam o barebacking queiram, necessariamente, adoecer e morrer. Ao contrário, muitos dos meus interlocutores parecem querer, paradoxalmente, mais vida, mesmo que seja sentida em um instante selvagem e abrupto, aparentemente orientado por uma força natural ou instintiva, valorizando o tempo curto ou de maximização do prazer imediato, porém intenso e real. Nos diferentes relatos sobre o barebacking, de forma convergente a outros discursos mais genéricos sobre o sexo sem camisinha, a sensação de liberdade, autonomia e excesso de prazer em decorrência do contato com o outro sem barreira ou incômodo, de forma mais natural, na pele $e_{2}$ parece provocar, mobilizar $e$ instigar os próprios atores:

Eu amo bareback, mas sem a intenção de pegar doenças. Gosto porque dá mais prazer e porque é $100 \%$ natural (Participante do fórum BAREBACK NO ESCURO).

Eu acho que quem já fêz sexo sem camisinha não o fêz com o propósito de se infectar com qualquer doença. Que atire a primeira pedra quem nunca fêz isso. Por risco ou

\footnotetext{
${ }^{15}$ As ideias de transgressão ou violação das fronteiras, em suas dimensões sagradas, corporais e emocionais, discutidas por Georges Bataille, são fundamentais para entender algumas das repercussões importantes e sentidos das práticas eróticas no cotidiano das pessoas, em situações diversas, quando o prazer parece vincular-se a uma experiência vivida no limite ou no excesso. Essa ideia do erotismo como continuidade profunda entre os seres (Bataille, 2004) pode, também, servir de modelo para compreender algumas das imagens ou efeitos produzidos através das interações online, quando as pessoas se sentem intimamente ou "organicamente" (Maffesoli, 2000) ligadas umas às outras, mesmo em um brevíssimo tempo, rompendo com as distâncias ou fronteiras espaço-temporais, podendo selecionar ou estabelecer contatos a partir de critérios menos formais.
} 
prazer? Prazer, óbvio (Participante do fórum motivações para o bareback).

Na minha opinião é só q o maior prazer do cara q curte barebacking está no tato, na pele. Não tem nada a ver com a presença ou ausência de perigo. É só pq sentir e saber q a pele tá em contato direto é muito mais gostoso (Participante do fórum motivações para o bareback).

O prazer real

O prazer realmente é muito maior. Eu sou passivo, mas quando ativo a camisinha várias vezes me fez brochar (Participante do fórum qual a melhor coisa no bareback).

Não tem comparação!

Vc sente realmente o pau te penetrando, sem o incômodo do látex que dá impressão que estão te introduzindo um tubo, sem contar que o cu fica áspero como se estivesse soprado bola de aniversário. O pau penetra com mais facilidade e não machuca e, além disso, dá muita satisfação tanto pra mim como pro cara quando ele goza dentro, já que fora é apenas mais um fetiche. Se o cara goza fora, então, eu me viro para levar a gozada na boca (Participante do fórum qual a melhor coisa no bareback).

MOTIVOS CONTRADITÓRIOS!!!!

Muito legal este tópíco. A maioria dos depoimentos falam sobre o único motivo principal de se fazer sexo sem camisinha, que é a busca pelo prazer. $\mathrm{O}$ instinto animal puro propiciado pelo sexo sem camisinha. Agora algumas pessoas aqui, corretamente, tentam se proteger, mesmo fazendo sexo sem camisinha, o que é legal tb. Particularmente faço sexo sem camisinha pois além do prazer que é mais intenso, é a sensação de liberdade pura, a contradição é que se procura através do prazer e da liberdade viver o máximo possível mas pode-se encurtar a vida mais cedo!!!! Prefiro o lema: viva 10 anos a mil e não 1.000 anos a dez!!! (Participante do fórum motivações para o bareback). ${ }^{16}$

${ }^{16}$ Tentei preservar ao máximo o estilo dos textos (mensagens) reproduzidos neste artigo. 
Prazer sem camisinha

Em algumas mensagens online, a relação entre prazer $e$ risco mostra-se de forma mais direta ou explícita. Acompanhando algumas das justificativas para a realização do barebacking, é possível traçar uma trajetória que liga o prazer ao perigo, ainda que esse trajeto apareça, muitas vezes, de forma confusa ou ambígua. O tesão ou emoção vivida através do medo, da aventura, da possibilidade de contrair alguma doença, da experiência de entrega, maior intimidade ou contato com o parceiro sexual, muitas vezes desconhecido, o incômodo da camisinha, o contato com o esperma, são aspectos importantes que se deslocam nos discursos sobre o barebacking. Entretanto, é preciso destacar que várias práticas que se mobilizam ou giram em torno do risco parecem querer intensificar emoções ou maximizar o próprio prazer. Em outras palavras, novas emoções são produzidas no contato com o risco, no desafio ou atravessamento das fronteiras ou linhas que separam corpos, identidades $e$ prazeres:

A emoção

É justamente essa sensação de aventura, de medo e o sentimento de se entregar totalmente à outra pessoa. Sou Bare Back e adoro, principalmente se for com desconhecido...)) (Participante do fórum $\mathrm{O}$ que te leva à praticar bare back).

Dá mais tesao...

O medo, a pele na pele, a camisinha machuca, é tudo é muito tesao. Faço ativo e passivo. Que delicia. Sem contar sentir a porra escorrendo... (Participante do fórum $\mathrm{O}$ que te leva à praticar bare back).

O tesao pelo medo

acho que tem um tesao no medo de fazer algo mais arriscado, é meio roleta russa, vc nao conhece o cara, e pode se contaminar.

Tesao parecido em pegar garoto de programa na rua, vc 
nao sabe se será assaltado ou nao. Isso intensifica o tesão (Participante do fórum qual a melhor coisa no bareback).

Entre outras coisas, o lance do contato fisico total, o tesão que o risco de pegar a doença dá, e pessoalmente por que gosto de esperma (Participante do fórum $\mathrm{O}$ que te leva à praticar bare back).

No que concerne às comunidades mais genéricas, que não estavam organizadas diretamente em torno do conceito de barebacking, é importante esclarecer que elas falavam sobre a preferência por "gozar dentro", posicionavam-se a "favor daquelas pessoas que gostam de transar sem camisinha", eram "dedicadas a quem prefere o sexo da forma mais natural que existe", enfatizavam "o prazer no sexo sem camisinha", estavam direcionadas para aqueles que "não vêem graça alguma em chupar bala com papel", preferem "no pelo" ou "na pele", como indicativo de um "sexo mais gostoso". Algumas dessas comunidades posicionavam-se de forma mais eloquente, enfatizando a preferência pelo sexo mais natural e destacando a perda de clima e prazer no sexo com borracha ou plástico. Entretanto, outras se apresentavam de forma ambígua e vacilante, na medida em que falavam sobre a desvantagem do uso da camisinha, sobre o incômodo de usá-la, mas também reconheciam a necessidade de algum cuidado ou de não uso em situações determinadas, como a confiança no parceiro. Alguns desses aspectos podem ser vislumbrados nas comunidades abaixo:

1) Odeio Camisinha (2.834 membros). Categoria: Pessoas Se você não suporta usar camisinha.

Se você odeia ter que cortar o momento para colocar aquele saco plástico.

Se você só usa por extrema necessidade.

Junte-se a essa comunidade.

2) Camisinha NEVER (57 membros). Categoria: Romances $e$ Relacionamentos 
Prazer sem camisinha

SE VC ABOMINA ESSE PEDAÇO DE BORRACHA (LATEX), QUE SÓ TE FAZ PERDER PRAZER, CORTA TOTALMENTE O CLIMA, ESSA É SUA COMUNIDADE!!!

E O PIOR..... SEMPRE QUE SE PRECISA NUNCA SE TEM!!!

"viva o momento, viva intensamente"

3) Prazer sem camisinha (632 membros). Categoria: Gays, Lésbicas e $\mathrm{Bi}$

"O valor das coisas não está no tempo que elas duram", mas na intensidade com que acontecem.

Por isso, existem momentos inesquecíveis, coisas inexplicáveis, e pessoas incomparáveis."

Por isso muito cuidado, e muito bom sim, mas pode fazer mal, por isso só transem sem a dita se conhecerem muito bem o companheiro de vcs, juízo meninos, e gozem muito!!!!!!!!!!!!!!!!!!!!!

4) Sem camisinha é mais gostoso! (746 membros). Categoria: Gays, Lésbicas e Bi

Essa comunidade é para aqueles guerreiros que gostam de transar sem preservativos. Gente na boa N BRINQUEM COM ISSO NÃO, vamos se previnir isso é sério, AIDS MATA!!!! CUIDE-SE!!!

Mais que é gostoso isso é:

Sexo sem camisinha é melhor que há.

Nessas comunidades constituídas apenas em torno da preferência pelo sexo sem camisinha ou que enfatizavam o incômodo de usá-la - mais genéricas em comparação às específicas de barebacking - havia uma quantidade expressiva de homens que se posicionavam heteroeroticamente (Costa, 2002) ${ }^{17}$ nos fóruns de discussão. Essa participação, entretanto, ocorria de forma mais intensa nas comunidades que não estavam na categoria de Gays, Lésbicas e Bi. Por outro lado, homens que demarcavam uma posição homoerótica em seus relatos $e$

${ }^{17}$ Utilizo essa denominação no mesmo sentido descrito pelo autor, ao discutir o homoerotismo, para não padronizar ou fixar práticas, identidades e desejos masculinos. Em muitas mensagens, esses homens enfatizavam o prazer de gozar dentro da mulher sem a camisinha. 
depoimentos também participavam de outras comunidades mais genéricas, mesmo em relação à identidade sexual do grupo. Isso não significa que a convivência era sempre harmoniosa, sem conflito, já que também ocorria algum tipo de preconceito ou discriminação através das estratégias discursivas utilizadas para referir-se a um membro ou grupo de participantes, por exemplo, através dos comentários: "vaza seu gay"; "vc é gay cara... que coisa"; "essa porra esta cheio de gay; porra aqui só tem viado". Mais especificamente em relação à comunidade denominada GOZAR DENTRO ${ }^{18}$ do Orkut, é interessante que a mesma expandia, em sua descrição, as configurações eróticas do corpo não limitadas às práticas sexuais entre homens e mulheres, ainda que seja comum no sistema erótico brasileiro ocorrer uma transgressão das normas heterossexuais reprodutivas, onde há espaço relativo para as misturas, deslocamento de sentidos $e$ inversões de papéis, com a erotização de todo o corpo, como é o caso do lugar de importância associado à "bunda", ao "cu" ou "ânus", fazendo diluir a primazia do intercurso genital (Parker, 1991).

Ressalto que distintos homens justificam a preferência pelo sexo sem camisinha através do discurso de maximização do prazer. Algumas imagens simbólicas ligadas à performance sexual masculina são recorrentes nesses discursos: a camisinha é "broxante"; "empaca a foda"; "aperta", "machuca", "o pau amolece", "tira o clima", "corta o tesão", "tira a sensibilidade", "diminui o prazer", "é comer ou chupar bala com papel". Entre aqueles que enfatizavam alguma dimensão heteroerótica em suas práticas sexuais desprotegidas, a referência ao ambiente "quente", "molhado", "melado", "úmido" e "macio" do órgão sexual feminino, ou mesmo ao prazer de "gozar dentro, encher a mina de porra", demonstra a valorização do contato com a pele, no pelo,

${ }^{18}$ Comunidade GOZAR DENTRO (2.295 membros). Categoria Culturas e Comunidade. Descrição: "Se você gosta de gozar dentro ou adora ter seu cuzinho ou bucetinha sendo enchidos com uma porra bem quentinha, entre nesta comunidade... Afinal gozar dentro é muito bom..." 
na chapa, do couro no couro, da carne na carne, como forma de obtenção de maior prazer sexual. Nessa direção, alguns enunciados sobre o sexo sem camisinha podem provocar tensões e confusões diante das concepções difundidas sobre $\mathrm{O}$ barebacking, principalmente quando as pessoas passam a valorizar o prazer momentâneo, sensorial, "bem aproveitado", natural, do sexo sem camisinha:

Morrer em virtude de ter feito muito sexo (e sendo bem aproveitado) num tira o mérito pra ninguém. Pelo contrário!

Eu também, só gosto do contato entre as carnes. Porra de camisinha! Camisinha é papo de Sandy \& Junior! (Participante do fórum 'Sou Mais ir no Pelo')

(...) Eu gosto de muita putaria e adoro gozar dentro... jah comi tanta mina q gozei dentro sendo q nem sei quem eh a puta... vai no pelo mesmo!!!

o foda eh q eu tenho um medo da porra de fazer exames... pq será neh?!?!

mas assim... eu vivo de momento... se to no apetite e nw tem camisinha o q acontece??? EU FODO MAIS GOSTOSO AINDA PQ COM CAPA EH FODA...

tenho varios amigos q sempre fodem sem camisinha tbm!!! (Participante do fórum 'Adoro Gozar Dentro').

Gozar dentro é tudo de bom!!! Seja na bucetinha, no cuzinho ou na boquinha, é mto bom, o fogo do momento! Ah! (Participante do fórum 'Adoro Gozar dentro')

So transo se for pra gozar dentro!

Odeio gozar fora ou transar de camisinha.

Sexo foi feito pra ser feito assim, sem camisinha e gozar dentro. Se não for assim não tem graça, prefiro tocar punheta (Participante do fórum 'Adoro Gozar dentro').

Tem que ir na chapa

porra nao tenha tesão nenhuma com camisinha,mai gozar fora tb ta por fora. 
tem que gozar dentro e torcer pra nao engravidar.. (Participante do fórum 'Sou Mais ir no Pelo')

Tem que transar sem!

Sentir o que Deus te proporcionou, a sensação do quente e do molhado, encher a mina de porra! (Participante do fórum 'No Camisinha Yes Meter no Pêlo')

Em uma das comunidades selecionadas do Orkut (comunidade Odeio Camisinha), a partir de um fórum de discussão criado por mim para discutir a diferença entre barebacking e sexo sem camisinha, alguns homens se posicionavam como heterossexuais e procuravam localizar e fixar a prática do barebacking dentro do grupo de homossexuais. A partir de um discurso heteronormativo (Butler, 2003; Seidman, $1994)^{19}$, para eles, o que estaria em questão no barebacking seria, fundamentalmente, o prazer em correr riscos, enquanto o não uso da camisinha entre heterossexuais implicaria apenas a busca pelo maior contato ou prazer sexual. O discurso heterossexual coloca o gay, homossexual, na posição de quem busca ou desafia o risco $e$ as doenças sexualmente transmissíveis, ou mesmo de quem já é soropositivo. Esse discurso trabalha com a polaridade risco-prazer, colocando um conjunto de práticas e seus elementos em um

\footnotetext{
${ }^{19}$ Utilizo, assim, a ideia de heteronormatividade a partir de uma leitura queer, que ressalta uma dimensão política de organização social, tomando como princípio padrões e modelos heterossexuais. Para Seidman (1994), a teoria queer muda o debate de uma preocupação exclusiva com a homossexualidade para o foco na heterossexulidade como um princípio de organização social e político, bem como da política de interesse de uma minoria para a política de conhecimento e da diferença. Ainda segundo o autor, o central na teoria queer é desafiar a crença em um sujeito ou identidade homossexual percebido como estável e unificado. Nessa perspectiva, as identidades são sempre múltiplas, fluidas, com uma infinidade de combinações e interseções (através das modalidades de gênero, sexo, idade, classe social, etc). Dessa forma, como enfatiza Butler (2003), qualquer construção específica da identidade é sempre arbitrária, instável, produzindo exclusões e oposições, corpos abjetos, no sentido de expulsar o que parece estranho ou fora do lugar.
} 


\section{Prazer sem camisinha}

respectivo lugar, buscando diferenciar e separar o que pode parecer estranho, "estúpido" ou "patológico". Nessa organização de condutas e desejos, esses homens parecem querer restabelecer uma ordem social, identitária, na qual eles não seriam confundidos ou misturados no contato com o outro, problemático, desordenado, fora da margem, portanto, mantendo as linhas da fronteira mais claramente definidas (Bauman, 1998a; Douglas, 1991; Rubin, 1984). ${ }^{20}$ Esses posicionamentos discursivos utilizados para definir uma identidade - barebacker e não barebacker, heterossexual e homossexual - demarcam habitus ou práticas distintivas (Bourdieu, 1997) entre os homens:

Augusto...

São coisas totalmente diferentes, em primeiro lugar o termo "Bareback" ou seja "cavalgar sem sela" é um termo restrito ao círculo homossexual, na verdade um "Barebaker" álém de não transar com camisinha o faz também pelo prazer de correr o risco, pela adrenalina. No meu caso, e creio que no caso da maioria que frequenta essa comunidade, não gosto de camisinha, entretanto, não sinto qualquer prazer em correr risco e tão pouco sou homossexual (Participante do fórum 'Vc é bareback?').

\footnotetext{
${ }^{20}$ Sem dúvida, essas leituras foram importantes para a discussão sobre as linhas e fronteiras que organizam o mundo social, colocando os estranhos ou diferentes em seus devidos lugares. Para Gayle Rubin (1984), há toda uma hierarquia de valores sexuais que separa o que é tido como "bom" e "mal" sexo, quando se coloca no outro lado da "margem" homossexuais promíscuos, sadomasoquistas, fetichistas, transexuais, tidos como incapazes de desenvolver afeição, amor, escolha livre ou transcendência. Conforme a autora, os discursos sobre sexo, sejam eles religiosos, psiquiátricos, populares ou políticos, estabelecem uma linha imaginária entre ordem e caos sexual, ou seja, o que é tido como seguro ou saudável de um lado e perigoso de outro. Esta estratificação sexual é importante para problematizar alguns valores que separam, diferenciam e distribuem determinadas relações ou práticas sexuais masculinas a partir de limites ou fronteiras de normalidade, tendo como referência o modelo heterossexual monogâmico e reprodutivo.
} 
(...) Transar sem camisinha envolve um risco e é feito geralmente em nome do prazer. Pelo que sei, a diferença entre alguém que simplesmente não gosta de usar camisinha e um "barebacker" está em que, enquanto o prazer do primeiro deriva apenas do contato físico direto entre os órgãos sexuais durante o sexo, o prazer do segunda deriva JUSTAMENTE (ou pelo menos principalmente) do RISCO de contrair uma DST. Tanto é que sabe-se que os barebacker organizam orgiais em que há sabidamente um soropositivo entre os participantes, sem que os demais saibam sua identidade (Participante do fórum " Vc é bareback?').

O termo bareback (transar sem camisinha), é bem mais falado por homossexuais! Na verdade...pode-se encontrar muito bareback em filmes pornô gay,e uma coisa: na maioria dos casos, os caras atores de filmes $\mathrm{q}$ fazem bareback são soropositivos! Isso é um ponto negativo $e$ positivo ao msmo tempo, pois sendo eles positivos, um pode atrapalhar o vírus do outro, e até mesmo o controle dos remédios q eles tomam. Pelo termo bareback, eu consideraria todos os homossexuais q fazem sexo sem camisinha...e não os outros... (Participante do fórum 'Vc é bareback?').

Caro amigo...

Duas coisas totalmente diferentes...

a maioria (acho eu) dos participantes desta comunidade, ODEIAM usar camisinha mais usam (me corrijam se eu estivér errado).

Transar com várias pessoas do mesmo sexo sabendo que pode contrair uma DST é no mínimo EXTUPIDEZ.

Eu realmente estou sabendo dessa merda de prática agora, e não vejo nenhuma semelhança com os temas abordados por nós aqui nessa comunidade.

Resumindo... BAREBACK pra ser do jeito que é, só poderia ser invenção de viado estúpido.

Sem mais... (Participante do fórum 'Vc é bareback?'). 
Prazer sem camisinha

Conforme aparece no último comentário, o fato de os membros da comunidade odiarem usar a camisinha não significa que, necessariamente, todos deixam de utilizá-la, e em qualquer situação. Esse aspecto também está presente em outros discursos homoeróticos. Alguns homens afirmam não usar camisinha apenas com um parceiro fixo ou de confiança. De acordo com o que aparece nas mensagens dos fóruns, incluindo alguns dos comentários destacados acima, a linha que separa o barebacking do sexo sem camisinha pode apresentar-se de forma controversa $e$ muito tênue. Considerando os comentários destacados, o barebacker seria um homossexual que busca desafiar o risco. Para estes homens, ainda que o risco esteja presente nas práticas (hetero)sexuais desprotegidas, o que comanda ou justifica a prática é "simplesmente" a busca de prazer. O risco surge como uma contingência do sexo sem camisinha, portanto, sem nenhuma intencionalidade de desafio.

No entanto, a partir da perspectiva dos que se consideram praticantes do barebacking, a intencionalidade (desafio) do risco nem sempre estará presente de forma clara ou decisiva. Nessa direção, vale destacar a opinião de alguns participantes de fóruns que procuram não diferenciar a prática do barebacking pela identidade sexual, tampouco marcam a diferença pela supervalorização do risco, aproximando ou colocando heterossexuais e homossexuais na mesma categoria, fazendo referência fundamentalmente ao sexo sem camisinha:

1) Bareback é transar sem camisinha.

Mas tem muito hétero que transa e num tá nem aí.

Olha a quantidade de mulheres solteiras que ganham nenénm.

Tudo transando sem camisinha e jogam a culpa da promiscuidade em cima dos viados.

Hipocrisia (Participante do fórum ' Vc é bareback?').

2) Fazer sexo sem camisinha é praticar bareback.. voce pode nao sentir prazer mas fazer com camisinha.. mas se voce pratica sem é um "barebacker".. quando se confia $e$ 
gosta nao vejo nenhum problema.. (Participante do fórum $1 \mathrm{O}$ QUE ROLA NO BAREBACK?).

3) É LEITE DENTRO MESMO.

bareback é (montar sem arreios)ou seja quando vc monta numa pica sem camisinha é o mesmo q montar num cavalo sem arreios ou seja:sem proteção alguma,daí a palavra BAREBACK. (Participante do fórum 2 O QUE ROLA NO BAREBACK?).

Seria um equívoco considerar o discurso da maximização do prazer sem problematizar os conflitos $e$ as tensões vividas por diferentes pessoas quando reconhecem algum tipo de necessidade ou obrigação para o uso da camisinha em detrimento de seus próprios prejuízos sensoriais, dificuldades ou incômodo. Nos diferentes fóruns acompanhados, compartilha-se um discurso de que o sexo sem camisinha é melhor ou, como define um participante, "é outro mundo (...) quente, úmido, macio, de prazeres mil". Nesse cenário de ganhos e perdas sensoriais "borracha ou plástico que aperta", "corta o tesão", "tira a sensibilidade ou o clima" - mobiliza-se também um discurso sobre o momento ou situação limite em que o uso da camisinha deve ser considerado, da mesma forma em que dilemas e conflitos podem ser vividos quando este limite é ultrapassado. Nessa direção, estratégias diversas podem ser mobilizadas para contornar alguns desses dilemas ou mesmo para justificar o sexo desprotegido, como a existência de um/a parceiro/a fixo/a ou de confiança, em situações extremas de excitação ou de perda de consciência, por exemplo, com o uso do álcool. Finalmente, no jogo sensorial entre perdas e ganhos, algumas pessoas podem reconhecer a necessidade de uso da camisinha, mas admitem a "não adaptação" em usá-la, preferindo o prazer obtido no "sexo de verdade".

Aperta, é ruim, tira o clima !!

Enfim... só usar no limite ! (Participante do fórum 'Quem Aqui

Nunca Conseguiu com a Maldita?'). 
Prazer sem camisinha

Diferença? Porra, não é diferença, é outro mundo. É um mundo quente, úmido, macio, de prazeres mil, hahahha.

Não aquele saco de super mercado no pinto.

Pra quem dá 3-4 de vez, dar meia com esse troço, só por obrigação! (Participante do fórum 'Faz Diferença').

Sexo sem camisinha eh bom d+

no meu caso, eu não sinto praze rnenhum, pq todas as camisinahs od mercado apertam muito meu pau! qdo ele alcança $100 \%$ d eereção! jontex então, a pica fica roxa, quase cai, fica gelada de tanto sangue parado..uma merda! quem tem pau grosso sofre! e nada como sentir a bucetinha engolindo e molhanod meu pau... hmmmmmm pena $\mathrm{q}$ por causa de todas essa doenças eu acabomesmo eh trepando pouco, pois poucas são as pessoas d econfiança! (Participante do fórum 'Pq vc curte').

Eh Demais!!!

sem camisinha vc sente a buceta!!o calor!!a pica entra e sai gostoso,nossa que delicia!!!!camisinha eh barrote!!pena q tem q usar!!

mas quando eu tomo umas e outras ainda faço umas besteiras mas depois a conciência pesa!!

Foda!!! (Participante do fórum 'Pq vc curte').

BOM APESAR DA NECESSIDADE NÃO CONSIGO ME ADAPTAR COM A TAL QUANDO DIZEM QUE COM ELA É IGUAL NÃO É NEM SOMBRA O GOSTOSO É SENTIR O CALOR DA BUCETA ELA MOLHANDO SEU PAU ISSO SIM É SEXO (Participante do fórum 'Pq vc curte').

\section{Considerações finais}

Existem diversos aspectos implicados quando se discute ou se reconhece abertamente que o sexo sem camisinha é uma prática comum na vida de muitas pessoas. Estamos acostumados a relacionar o sexo sem camisinha aos estudos sobre comportamentos e práticas de risco para as infecções sexualmente transmissíveis, incluindo o HIV. Nessa perspectiva, o risco é percebido em uma dimensão negativa, devendo ser controlado 
através dos conhecimentos acumulados, recursos e estratégias disponíveis. O desenvolvimento de ações e programas específicos busca expandir ou melhorar a vida das populações segundo critérios estabelecidos pelas agências de controle do risco.

Em contrapartida, ao longo da minha pesquisa, os comportamentos e as práticas de risco para HIV seguiram outra direção. Como sugerem os fóruns e comunidades do Orkut, diferentes pessoas passam a discutir, reconhecer ou destacar os aspectos positivos (prazerosos) do sexo sem camisinha, ou seja, a intensificação do prazer sensorial no contato pele a pele ou do sexo natural. Vale lembrar que várias comunidades não estão classificadas como Gays, Lésbicas e Bi. Um discurso, portanto, que segue na contramão da Saúde, quando as políticas de prevenção enfatizam o sexo seguro sempre.

Vale a pena retomar um aspecto discutido por Mary Douglas (1991) no sentido de dar a devida atenção ou reconhecer a existência daquilo que foge aos nossos padrões rigorosos de "pureza" ou de saúde. No momento atual, alguns elementos estranhos ao campo da saúde parecem ressurgir, conviver ou adquirir sentidos diversos no cotidiano vivido das pessoas. É o caso, por exemplo, da fascinação pelo perigo ou desconhecido, quando os parceiros sexuais têm, momentaneamente, a oportunidade de estarem juntos de forma mais intensa e livre, sem barreira ou obstáculo, em detrimento da possibilidade de infecção (ou reinfecção) por HIV.

Dessa forma, o risco também pode significar uma maneira de desafiar ou afrontar a morte para dar sentido à existência (Le Breton, 2000). ${ }^{21}$ A morte simbolicamente superada permite que o

${ }^{21}$ Le Breton (2000) afirma que toda busca de limites, em última análise, solicita a morte para garantir a existência. Esse desafio marca a posição do indivíduo no mundo e afasta o medo difuso ligado à indeterminação dos sentidos e dos valores. Nessa perspectiva, ao superar os limites e dar um novo sentido para a sua existência, o indivíduo "busca sua marca, testa o que ele é, aprende a se reconhecer, a se diferenciar dos outros, a restaurar um valor para a sua existência" (Id.ib.:17). Esse novo "aventureiro" encontra respaldo nas formas ocidentais do individualismo contemporâneo, em que ocorre uma "confusão de 
Prazer sem camisinha

indivíduo continue a viver a partir de uma nova legitimidade. Ela favorece, portanto, uma intensidade renovada do viver. Em vários momentos da pesquisa, a ruptura ou perturbação das fronteiras ou os limites estabelecidos socioculturalmente parecem produzir um suplemento de prazer.

Duas dimensões analíticas estão intimamente vinculadas no sexo desprotegido, mas parecem omissas nos discursos mais oficiais (científico-governamentais): o prazer sensorial do contato pele a pele $e$ as emoções suplementares em consequência do próprio risco, ou seja, de seus efeitos sobre o corpo e a vida, mas principalmente em decorrência de uma ação que rompe com as normas estabelecidas. Entretanto, o que parece ligar os discursos (sexo sem camisinha e barebacking) é a busca por experiências mais naturais e livres, sensações e prazeres mais intensos. Portanto, o que está em jogo no sexo desprotegido é a possibilidade de maximização do prazer no contato mais íntimo com o outro.

É importante lembrar que este artigo não discute todos os diferentes aspectos vinculados ao sexo sem camisinha, principalmente as práticas eróticas entre homens e mulheres, o que representa uma lacuna e possibilidade para futuras pesquisas dentro ou fora da internet, por exemplo, o discurso sobre o risco de gravidez, sobre a eficácia do ato de gozar fora ou coito interrompido, e mesmo sobre a perspectiva das mulheres em relação ao sexo desprotegido. Ainda que a participação masculina tenha ocorrido de forma mais marcante nos fóruns acompanhados, não se deve negligenciar a presença das mulheres nesses espaços ao compartilharem um discurso sensorial, de prazer e satisfação em torno do sexo sem camisinha, aproximando ou fazendo dialogar as dimensões do perigo e do prazer em seus encontros sexuais.

referência" $e$ "descontinuidade do sentido". O indivíduo tende cada vez mais a se "autorreferenciar", a buscar em si mesmo o que antes procurava no interior da cultura e na companhia dos outros (Id.ib.:12). 
Estamos, portanto, diante de novas formas de socialização $e$ práticas cotidianas que põem em circulação algumas referências identitárias baseadas nas experiências sensoriais, vividas no presente, buscando maximizar as formas de prazer que desafiam os limites da saúde e do próprio corpo. Nessa perspectiva, o prazer é percebido como "ritualístico", extático (Conveney \& Bunton, 2003), comum em muitas culturas, para ressaltar uma experiência espiritualmente expandida, acompanhada de substâncias e ritmos que alteram os estados de consciência e o humor. Por exemplo, as culturas juvenis atuais, com a popularização das raves e do ecstasy, aparecem como forma de desburocratização da vida cotidiana, de liberação, prazer $e$ comunhão entre os participantes, portanto, uma maneira, "quase nostálgica", de retomar um tempo em que as sociedades produziam um "estar junto mais intenso", uma existência sensual (Coveney \& Bunton, 2003:173).

Finalmente, existem vários enunciados sobre o sexo sem camisinha que não fazem referência direta aos termos barebacking ou barebacker. É importante assinalar que o conceito de barebacking foi usado, fundamentalmente, em diferentes relatos como sexo sem camisinha ou sem borracha, muitas vezes, sem delimitar a situação ou contexto a que se aplicava, ainda que alguns dos meus interlocutores tenham especificado seu contexto de uso $^{22}$. Vale lembrar também que, entre os usuários da internet, o conceito de barebacking é utilizado, basicamente, por homens que fazem sexo com homens. Em contrapartida, alguns membros dos fóruns de discussão do Orkut, posicionados heteroeroticamente, não se consideram barebackers, exatamente pela ideia de prazer do risco ou de desafio das doenças (e da

${ }^{22}$ Alguns praticantes do barebacking procuram diferenciar o contexto ou situação em que ocorre o sexo desprotegido com o objetivo de delimitar o conceito de barebacking (e o barebacker). Algumas dessas dimensões analíticas dizem respeito à intencionalidade do ato, à extensão em que ocorre a prática sexual desprotegida ou mesmo à polaridade prazer do risco X prazer do contato total entre os parceiros. 
morte) ligada ao conceito. No entanto, em muitos relatos o prazer sensorial e de contato mais íntimo com o outro aparecem de forma marcante, colocando o risco em um plano mais secundário ou distante dos interesses em foco.

Para além de produzir uma dicotomia entre prazer e risco, inclusive porque esses elementos estão intimamente vinculados (Lupton, 1999) ${ }^{23}$, ainda que não se expressem de forma previsível, clara e coerente, é importante levar em consideração os diversos sentidos produzidos pelos potenciais barebackers. $\mathrm{O}$ que exige, também, o desenvolvimento de novos estudos (online e offline) para acompanhar a circulação $e$ usos dos termos barebacking $e$ barebacker em contextos e tempos diversos, bem como a forma como os novos discursos sobre o sexo sem camisinha passam a ser utilizados entre pessoas com múltiplos posicionamentos identitários.

Essas apropriações e deslocamentos de sentido em torno do sexo desprotegido devem entrar na pauta de discussão, principalmente porque as ações diárias nem sempre se conformam às identidades mais estáveis ou estabelecidas. Por exemplo, no caso de homens que se relacionam afetiva e sexualmente com outros homens, mas que não se enquadram, necessariamente, em nenhum padrão identitário, ou se posicionam diferentemente a partir de seus contextos interativos. Nessa perspectiva, é possível que homens e mulheres que se posicionam heteroeroticamente passem a incorporar (ou já estejam incorporando) o conceito de barebacking ou a criar novas categorias para focalizar o sexo sem camisinha em seu cotidiano, produzindo-se, também, uma

${ }^{23}$ Uma das perspectivas na discussão sobre o risco abordada por Deborah Lupton, principalmente no que diz respeito à transgressão das fronteiras $e$ oposições (dentro-fora, eu-outro, etc). Nessa perspectiva, o prazer está intimamente vinculado à ideia de transgressão (ou violação) de fronteiras, que incluem a separação dos corpos. Essa fronteira simbólica, que demarca comportamentos e que organiza os prazeres, produz ao mesmo tempo medo $e$ fascinação, mostrando-se, portanto, de forma ambivalente, tênue e instável. 
multiplicidade de sentidos. ${ }^{24}$ Nessa direção, a própria internet tem possibilitado a troca de experiência entre pessoas com trajetórias culturais e biografias diversas, mobilizando a capacidade criativa de seus atores.

Assim, é preciso reconhecer a existência do sexo sem camisinha, discuti-lo abertamente, considerá-lo como uma dimensão possível (e legítima) das experiências eróticas, bem como compreender os distintos interesses e sensações, as estratégias para não usar o preservativo $e$ os significados produzidos em torno das práticas sexuais desprotegidas. Para além de uma perspectiva moralizante, no sentido de atribuir e fixar valores como certo ou errado, bom ou mal, é preciso dialogar com essas práticas e discursos que fazem parte de cotidianos diversos, inclusive para entender ( $e$ admitir) os limites, dificuldades e outros prazeres vividos por atores concretos no momento em que surge a (não) necessidade do sexo seguro, bem como desenvolver ações ou programas que sejam pertinentes ao mundo da vida.

Por outro lado, é importante reconhecer que as relações eróticas na contemporaneidade adquirem características de consumo (Bauman, 1998b), quando as pessoas buscam colecionar sensações novas, considerando a infinidade de estímulos disponíveis através de meios e canais diversos. Nesse cenário, o prazer deve ser usado e substituído sempre que perder sua novidade (Bauman, 2004).

Vivemos um tempo promissor em vários sentidos, inclusive por imaginar realidades psicológicas menos rígidas, sufocantes, no

\footnotetext{
${ }^{24}$ Recentemente, já em 2010, visitando uma comunidade do Orkut sobre o barebacking, denominada BAREBACKers, criada em 2007 (descrita na categoria Outros e com 1.166 membros), encontrei um fórum de discussão sobre "bareback heterossexual". Na descrição do fórum, eram feitas as seguintes perguntas: alguem ja ouviu falar de bareback heterossexual?? Tem coisa mais gostosa que gozar no quentinho de uma buceta feminina??? No decorrer das respostas, um dos participantes postou uma mensagem com o título Bareback Hetero tem nome CREAMPIE, respondendo: procure pelo termo no Google, creampie também é a ultima moda como bareback na europa e EUA.
} 
Prazer sem camisinha

sentido de serem mais permissivas e transicionais (Costa, 2004). Entretanto, a tão almejada felicidade sensorial também não é (definitivamente) alcançada, já que precisa ser sempre renovada, podendo gerar mais ansiedade e frustração. Abre-se, aqui, um novo desafio. Ao mesmo tempo em que é importante reconhecer a liberdade criativa das pessoas, inclusive para que possam mobilizar formas e espaços alternativos de produção de novos prazeres (e desejos), no sentido de recriar o gosto pela vida, devemos, também, problematizar a fragilidade do tempo atual em relação aos modelos e referências importantes para a construção de projetos comuns ou mais coletivos.

\section{Referências bibliográficas}

BAKHTIN, Mikhail. The Dialogic Imagination. Austin, University of Texas Press, 1998 [1981].

. L'ouvre de François Rabelais et la culture populaire au Moyen Age et sous la Renaissance. Paris, Éditions Gallimard, 1970.

BatAille, Georges. O erotismo. São Paulo, Arx, 2004.

BAUMAN, Zygmunt. Amor líquido: sobre a fragilidade dos laços humanos. Rio de Janeiro, Jorge Zahar Ed., 2004.

. O mal-estar da pós-modernidade. Rio de Janeiro, Jorge Zahar Ed.,1998a.

. On Postmodern Uses of Sex. Theory, Culture \& Society, 15 (3-4), 1998b, pp.19-33.

BOURDIEU, Pierre. Razões práticas: sobre a teoria da ação. Campinas-SP, Papirus, 1997.

BROWN, Graham, MAYCOCK, Bruce \& BuRNS, Sharyn. Your picture is your bait: use and meaning of cyberspace among gay men. The Journal of Sex Research, vol.42 (1), 2005, pp.63-73.

BUTLER, Judith. Problemas de gênero: feminismo e subversão da identidade. Rio de Janeiro, Civilização Brasileira, 2003. 
Luís Augusto Vasconcelos da Silva

CONVENEY, John \& BUNTON, Robin. In pursuit of the study of pleasure: implications for health research and practice. Health, 7(2), 2003, pp.61-179.

COSTA, Jurandir Freire. O vestígio e a aura: corpo e consumismo na moral do espetáculo. Rio de Janeiro, Garamond, 2004.

. A inocência e o vício: estudos sobre o homoerotismo. Rio de Janeiro, Relume-Dumará, 2002.

DOUGLAS, Mary. Risk and Blame: essays in cultural theory. London and New York, Routledge, 1994.

. Pureza e perigo: ensaios sobre as noções de poluição $e$ tabu. Lisboa, Edições 70, 1991.

ELFORD, Jonathan. Changing patterns of sexual behaviour in the era of highly active antiretroviral therapy. Current Opinion in Infectious Diseases, 19 (1), 2006, pp.26-32.

ELIAS, Norbert. O processo civilizador. Vol. 2. Rio de Janeiro, Jorge Zahar Ed., 1993.

FouCAULT, Michel. História da sexualidade I: a vontade de saber. Rio de Janeiro, Graal, 2001 [1988].

FRY, Peter. Para inglês ver: identidade e política na cultura brasileira. Rio de Janeiro, Zahar Editores, 1983.

GROSZ, Elizabeth. Volatile bodies: toward a corporeal feminism. Indiana University Press, 1994.

HALkITIS, Perry, PARSONS, Jeffrey \& WiLTON, Leo. Barebacking among gay and bisexual men in New York city: explanations for the emergence of intentional unsafe behavior. Archives of Sexual Behavior, 32 (4), 2003, pp. 351-357.

KRISTEVA, Julia. Powers of Horror: an essay on abjection. New York, Columbia University Press, 1982.

Le Breton, David. Conduites à risque. Paris, Presses Universitaires de France, 2002.

. Passions du risque. Paris, Éditions Métailié, 2000 [1991]. 
Prazer sem camisinha

LÉVY, Joseph, GARNIER, Catherine \& THOER-FABRE, Christine. Du viagra à internet: technologisation de la sexualité et enjeux politiques. Bulletin d'Histoire Politique, 15 (1), 2006, pp.25-35.

LUPTON, Deborah \& TULLOCH, John. "Risk is part of your life": risk epistemologies among a group of australians. Sociology, 36(2), 2002, pp.317-334.

LUPTON, Deborah. Risk. London and New York, Routledge, 1999.

. The emotional self. London/New Delhi, SAGE Publications/Thousand Oaks, 1998.

MAFFESOLI, Michel. Le temps des tribus: le déclin de l'individualisme dans les sociétés postmodernes. Paris, La Table Ronde, 2000 [1988].

MANSERGH, Gordon et alii. "Barebacking" in a diverse sample of men who have sex with men. AIDS, 16(4), 2002, pp.653-659.

MORAIS, Cleber \& ROCHA, Diego. Porque existe tanto brasileiro no Orkut? $\mathrm{Ou}$ as redes sociais $e$ o homem cordial [http://reposcom.portcom.intercom.org.br/bitstream/1904/17829/1/R1 612-1.pdf - acesso em 20/08/2007].

PARKER, Richard. Corpos, prazeres e paixões: a cultura sexual no Brasil contemporâneo. São Paulo, Best Seller, 1991.

POTTER, Jonathan. Representing reality: discourse, rhetoric and social construction. London, Sage Publications, 1997.

RIOS, Luís Felipe. Parcerias e práticas sexuais de jovens homossexuais no Rio de Janeiro. Cad. Saúde Pública (19), suplemento 2, 2003, pp.S223-S232.

Ross, Michael W. Typing, doing, and being: sexuality and the internet. The Journal of Sex Research, 42, 2005, pp.342-352.

; TIKKANEN, Ronny \& MANSSON, Sven-Axel. Differences between internet samples and conventional samples of men who have sex with men: implications for research and HIV interventions. Social Science \& Medicine, 51, 2000, pp.749-758.

RUBIN, Gayle. Thinking sex: notes for a radical theory of the politics of sexuality. In: VANCE, C. S. Pleasure and danger: exploring female 
sexuality. Boston/London, Melbourne and Henley/Routledge \& Kegan Paul, 1984, pp.267-319.

SEIDMAN, Steven. Queer-ing sociology, sociologizing queer theory: an introduction. Sociological Theory, 12(2), 1994, pp.166-177.

SEMERENE, Bárbara. Abrindo as portas dos salóes virtuais. In: PORTO, Sérgio. (org.) Sexo, afeto e era tecnológica: um estudo de chats na internet. Brasília, Ed. Universidade de Brasília, 1999, pp.29-40.

SPINK, Mary Jane. Trópicos do discurso sobre risco: risco-aventura como metáfora na modernidade tardia. Cad. Saúde Pública, 17(6), 2001, pp.1277-1311.

; MEDRADO, Benedito. Produção de sentidos no cotidiano: uma abordagem teórico-metodológica para análise das práticas discursivas. In: SPINK, Mary Jane. (org.) Práticas discursivas e produção de sentidos no cotidiano: aproximações teóricas $e$ metodológicas. São Paulo, Cortez, 1999, pp.41-61.

SuAREZ, Troy \& MILLER, Jeffrey. Negotiating risks in context: A perspective on unprotected anal intercourse and barebacking among men who have sex with men - Where do we go from here? Archives of Sexual Behavior, 30(3), 2001, pp.287-300.

TURKLE, Sherry. Cyberspace and identity. Contemporary Sociology, vol. 28(6), 1999, pp.643-648.

WOLITSKI, Richard J. The emergence of barebacking among gay and bisexual men in the United States: a public health perspective. Journal of Gay \& Lesbian Psychotherapy, 9(3/4), 2005, pp.9-34. 